\title{
THE RELEVANCE OF THE DEVELOPMENT AND IMPLEMENTATION OF QUALITY SYSTEM IN CLINICAL DIAGNOSTIC LABORATORIES
}

DOI: 10.36740/WLek202009233

\author{
Rymma F. Yeromenko ${ }^{1}$, Maryna 0. Ostapets ${ }^{1}$, Olexiy B. Datsenko², Olga M. Lytvynova' ${ }^{1}$, Hanna L. Lytvynenko' \\ 'NATIONAL PHARMACEUTICAL UNIVERSITY, KHARKIV, UKRAINE \\ ${ }^{2}$ MUNICIPAL NON-PROFIT ENTERPRISE "CITY CLINICAL HOSPITAL No 2 NAMED AFTER PROF. A. A. SHALIMOV" OF THE KHARKOV CITY COUNCIL, \\ KHARKIV, UKRAINE
}

\begin{abstract}
The aim: To analyze the implementation of international standards ISO series, which ensures the creation of uniformity of measurements, the ability to use the results of laboratory studies to ensure their reliability and reproducibility.

Materials and methods: The samples were taken from the ISO documents, the Regulation and the Quality Decree of clinical diagnostic laboratory (2017) that is the object of the research activities of the clinical diagnostic laboratory "City clinical hospital № 2 named after Prof. A. A. Shalimov".

Conclusions: The introduction of international standards of the ISO series into the domestic laboratory practice ensures the creation of a single medical space, the uniformity of measurements, the possibility of using the results of laboratory studies with an increase in their reliability and reproducibility.
\end{abstract}

KEY WORDS: laboratory research, quality system, state standards

Wiad Lek. 2020;73(9 p. II):2073-2075

\section{INTRODUCTION}

One of the most important components of the Ukrainian health care system of Ukraine is clinical laboratory diagnostics, which is of national importance for the preservation and improvement of public health $[7,10]$. Modern laboratory diagnostics provides medical and diagnostic assistance to patients in assessing the state of health, diagnosis of diseases, monitoring the results of treatment, further prognosis of the disease and quality of life [2].

Laboratory research is one of the most important segments in healthcare. Today, one of the main tasks of the clinical laboratory diagnostics service is to improve the quality of laboratory tests, which can be implemented by using modern technologies and equipment, improving laboratory methods and procedures, and changing outdated principles and stereotypes of the quality management system [3]. From 30 to $45 \%$ of cases of diseases cannot be diagnosed correctly without objective examination data, among which the results of clinical laboratory studies are 60-80\% [5].

In laboratory medicine in developed countries, the error range is $0.1-3.0 \%$ of the total results of laboratory studies (errors at all stages of research). Therefore, in connection with the solution of this problem, it is urgent to develop and implement the requirements of ISO standards for medical laboratory practice. This will reduce the level of errors in laboratory research. Up to modern quality standards include: ISO 15393, ISO 15194, ISO 15195, ISO 17511, ISO 18153, ISO 17025, ISO 15189, ISO 10012, which establish requirements for the creation of reference systems for medical laboratory research $[7,9,10]$. Standards are the main condition for the suitability of the results of medical laboratory tests, they provide comparability of results in time and space $[1,6]$. It is also important to analyze the international experience of accreditation of clinical diagnostic laboratories, the development of stages of implementation of the requirements of DSTU ISO 10012:2005, the basic procedures of the quality system of the laboratory, in particular the Regulations of the laboratory, Quality Decree and laboratory Passport.

\section{THE AIM}

To study the feasibility and importance of the implementation of the state standard ISO 10012:2005 in the field of clinical laboratory diagnostics.

\section{MATERIALS AND METHODS}

The object of the research is the activity of the clinical diagnostic laboratory of the municipal non-profit enterprise (KNP) "City clinical hospital № 2 named after Prof. A. A. Shalimov" of the Kharkiv city Council. The material was ISO documents, the Regulations on clinical diagnostic laboratory (2017).) [1, 4, 7,9,8], Quality Decree of clinical diagnostic laboratory. The methods stated in the certificate (according to the appendix) are confirmed in accordance with the requirements of DSTU ISO 10012: 2005. 
Measuring equipment (a hematology analyzer, photoelectric concentration colorimeter KFK-2, microscope Biolan R-11, immunoassay analyzer STAT-FAX 4700, chemistry analyzer RT-9200, AGKM-01, Exan-G, coagulometer K-3302 OPTIC photometer Laura Smart urine analyzer, gas chromatograph Agilent 7890 B, mass detector Agilent 5977 B, pipette dispenser P-1, urometer) and accessories used according to the normative documents, which are presented in the laboratory Passport.

\section{REVIEW AND DISCUSSION}

The main function of the clinical diagnostic laboratory of KNP “City clinical hospital № 2 named after Prof. O. Shalimov "according to the" Regulations on clinical diagnostic laboratory "(2017) is a timely and qualitative examination of patients. The definition of indicators in biological materials is carried out using the following equipment: a hematology analyzer, photoelectric concentration colorimeter KFK-2, microscope Biolan R-11, immunoassay analyzer STAT-FAX 4700, chemistry analyzer RT-9200, AGKM-01 and Exan-G (for glucose definition in blood serum), coagulometer K-3302 OPTIC photometer Laura Smart urine analyzer, gas chromatograph Agilent 7890 B, mass detector Agilent 5977 B, the pipette dispenser P-1, urometr. The analytical activity of the laboratory includes: the analysis of forms and methods of the analytical activity; the introduction of advanced methods and the directions of laboratory service, providing the laboratory with the information about new research methods, the equipment and auxiliary materials, normative documents; the improvement of the system of internal and external quality control of laboratory studies.

DSTU ISO 10012: 2005" Measurement control systems. The Requirements for measurement processes and measuring equipment" was developed and implemented in clinical and diagnostic laboratory of KNP " City clinical hospital № 2 named after Prof. O. O. Shalimov "of the Kharkiv city Council, as evidenced by the Certificate № 01-0009/2017 from 21.02.2017. The Laboratory conducts laboratory studies: hematological, general clinical, biochemical, serological, cytological, toxicological and microbiological in accordance with the profile of the laboratory and in the volume that corresponds to the scale and needs of the medical institution. Quality requirements are set once every three years, the implementation of which is certified by the procedure of analysis by senior management.

The scope of measurement objects and processes of the measurement system, which is covered by the Certificate, includes the research:

- blood serum - the determination of triglycerides, high-density lipoproteins and cholesterol by enzymatic-photometric method; uric acid by phosphoric-tungsten reaction; potassium and sodium by ion selective method; cholesterol and low-density lipoproteins; triglycerides with the calculation of very low-density lipoproteins; cholesterol and low-density lipoproteins with the calculation of atherogenicity coefficient; surface antigen hepatitis B express test; antibodies to HCV express test; antibodies to troponin, myoglobin, express test of creatinine phosphokinase-MB; antibodies to Helicobacter pylori by express test; of alanine aminotransferase and aspartate aminotransferase by kinetic method; bilirubin for diazoreaction in the presence of the accelerator; the activity of $\alpha$-amylase by Karavey alloplastic method of resistant starch substrate; activity of alkaline phosphatase by kinetic method; rheumatoid factor by latex test; C-reactive protein by latex test; total protein by biuret reaction; protein fractions by turbidimetric method,by method of gel electrophoresis; creatinine by Jaffe colour reaction; urea by the colour reaction with diacetylmonooxime; thymol samples; glucose by glucoseoxidase method; glucose for AGKM-01 and Exan-G;

-blood venous- morphological study of blood cells with differential counts and morphology of red blood cells using Papenheim staining; counting the number of erythrocytes and leukocytes by impedance method using a hematology analyzer; hemoglobin by photometrical method using a hematology analyzer; carboxyhemoglobin by Fervust-Minex method; the clotting time by Lee-White; blood group system $\mathrm{AB} 0$ with the help of test reagents anti $\mathrm{A}$, anti $\mathrm{B} ; \mathrm{RH}$ factor with a test reagent anti- $D$; the method of dehydration of fructose phosphoric acid; tension immunity to tetanus by ELISA; study on lupus erythematosus cells by Zinkham method; determination of erythrocyte sedimentation rate by Panchenkov micro-method;

- capillary blood -the platelet counts by impedance method and using a hematological analyzer; reticulocytes after staining them brilliant blue, Azur I, Azur II; determining the time of coagulation by Moravitz; duration of bleeding by Duke; blood test for malaria by thick drops and smears;

-plasma - determination of fibrinogen by Klaus; partial thromboplastin time with adding calcium chloride; degree of coagulation by Fuene-Ita method; plasma tolerance to heparin; factors of prothrombin complex; prothrombin time with calculation of international normalized ratio;

-urine - determination of physico-chemical properties of urine; $\mathrm{pH}$ using the indicator bromthymol blue; specific weight using a urometer; the quality of the sample with $20 \%$ sulfosalicylic acid in a protein; the protein with the turbidity formed by the addition of $3 \%$ sulfosalicylic acid; the qualitative reaction for the presence of urine glucose using test strips "Glucotest"; the number of glucose by glucose oxidase method; microscopic examination of urine sediment in the native preparation; ketone bodies using the express method, quality test on bilirubin by reaction with iodine solution, amount of shaped elements in $1 \mathrm{ml}$ of urine by Nechiporenko method; red blood cells and white blood cells using test strips;

- cerebrospinal fluid - conducting Jonne-Apelt reaction; counting cytosis using a counter; microscopic examination of drugs stained by Romanovsky method;

- duodenal content - determination of physical properties of bile; microscopic examination of bile in native preparation;

- gastric contents - determination of gastric acidity by titration; microscopic examination of gastric juice; 
- fecal - microscopic fecal examination; for occult blood, benzidine test; detection of the simpliest intestines in feces by native smear method with Lugol's iodine; smear on cryptospora stained by Romanovsky; identification of larvae in feces by Berman method and by the method of enrichment; - liquids of serous cavities-a microbiological study on the detection and identification of infectious agents; microscopic examination of the sediment of exudates and transudates; determination of physical properties of exudates and transudates; specific gravity using a urometer; protein 3\% sulfosalicylic acid;

- sputum - microbiological methods of sputum examination; - preanal scraping-detection of helminth larvae in preanalocular scrapings using a sticky strip.

Due to the internal and external quality control quantitative indicators of the clinical and diagnostic laboratory of the KNP "City clinical hospital № 2 named after Prof. A. A. Shalimov" of the Kharkiv city Council according to the results of the statistical report for 2018 are 504731 laboratory studies, including: general clinical - 111 777, hematological - 143373 , cytological - 108, toxicological - 2 135, biochemical - 218 741, bacteriological - 16 397, immunological - 11200.

Thus, the clinical and diagnostic laboratory has established, implemented and maintains a quality management system according to ISO 10012:2005 according to the scope of its activities, as well as ensures its further continuous improvement in order to improve the effectiveness and efficiency of measurement processes.

\section{CONCLUSIONS}

1. The introduction of international standards of the ISO series into the domestic laboratory practice ensures the creation of a single medical space, the uniformity of measurements, the possibility of using the results of laboratory studies with an increase in their reliability and reproducibility.

2. Development and implementation of the quality system according to the requirements of the standard DSTU ISO 10012:2005 "Measurement control system. Requirements to measurement processes and measuring equipment" in the activity of clinical and diagnostic laboratory of KNP "City clinical hospital № 2 named after Prof. A. A. Shalimov" of the Kharkiv city Council provides high quality of clinical and laboratory research.

3. The quality system of clinical diagnostic laboratory of KNP "City clinical hospital № 2 named after Prof. A. A. Shalimov" of Kharkiv city Council meets the requirements of ISO standards and is the key to protecting citizens of Ukraine from the consequences of inaccurate measurement results.

\section{REFERENCES}

1. Dayakar S., Pillai H. R., Kalpathodi S. et al. A Guide to Total Quality Management System (TQMS) in Molecular Diagnostics from Experiences in Seeking Accreditation and Implementation. SN Comprehensive Clinical Medicine. 2019;1(2):123-133.
2. Arbiol-Roca A., Dot-Bach D. Critical Issues and New Trends on Stat Tests in Clinical Laboratory. EJIFCC. 2019;30(1):59-66.

3. Barradas J., Sampaio P. ISO 9001 and ISO/IEC 17025: Which is the best option for a laboratory of metrology?the Portuguese experience. 2017; 34(3):406-441.

4. Berwouts S., Morris M. A., Dequeker E. Approaches to quality management and accreditation in a genetic testing laboratory. Eur J Hum Genet. 2010; 18(11):1-19.

5. Ceriotti F. The role of external quality assessment schemes in monitoring and improving the standardization process.Clin Chim Acta. 2014; 432: 77-81.

6. McKee Silva V. V., Duarte Ribeiro J. L. Acquiring laboratory accreditation - required activities. International Journal of Health Care Quality Assurance.2019; 32(1): 71-83.

7. DSTU EN ISO 15189:2015. Medical laboratory. Requirements for quality and competence.

8. Law of Ukraine "On Metrology and metrological activity" (as amended on 22.06.2017, № 2119-VIII).

9. Medical laboratories. Separate requirements for quality and competence ISO 15189-2009- 40.

10. Misyurova S. V., Dobrova V. Ye., Svid N.0., Otrishko I. A. Introduction of quality system according to the State standard ISO 15189: 2015 in laboratory of clinical diagnostics of the clinical diagnostic center of National Pharmaceutical University: applied aspects.Clinical pharmacy. 2018; 22(1): 28-33.

\section{ORCID and contributionship:}

Rymma F. Yeromenko: 0000-0001-8868-8935 A,F

Maryna O. Ostapets: 0000-0002-6900-5833 ${ }^{D}$

Olga M. Lytvynova: 0000-0002-0996-2500 ${ }^{B}$

Hanna L. Lytvynenko: 0000-0001-5727-5361 ${ }^{B}$

Olexiy B. Datsenko: 0000-0002-7428-8217 ${ }^{E}$

\section{Conflict of interest:}

The Authors declare no conflict of interest.

\section{CORRESPONDING AUTHOR \\ Hanna L. Lytvynenko \\ National University of pharmacy \\ 12 Kulikov str., 61002 Kharkiv, Ukraine \\ tel: +380679998513 \\ e-mail: litvinenko.79anna@gmail.com}

Received: 23.09 .2019

Accepted: 03.07.2020

\footnotetext{
A - Work concept and design, B - Data collection and analysis, C - Responsibility for statistical analysis, D -Writing the article, $\mathbf{E}$-Critical review, $\mathbf{F}$ - Final approval of the article
} 